\title{
LA-UR-21-31073
}

Approved for public release; distribution is unlimited.

Title: $\quad$ Three-Dimensional Site Effects at Mortandad Canyon, NM:I. Validation against ambient noise recordings of topography effects

Author(s): $\quad$ Mohammadi, Kami

Asimaki, Domniki

Larmat, Carene

Intended for: Report

Issued:

2021-11-05 
Disclaimer:

Los Alamos National Laboratory, an affirmative action/equal opportunity employer, is operated by Triad National Security, LLC for the National Nuclear Security Administration of U.S. Department of Energy under contract 89233218CNA000001. By approving this article, the publisher recognizes that the U.S. Government retains nonexclusive, royalty-free license to publish or reproduce the published form of this contribution, or to allow others to do so, for U.S. Government purposes. Los Alamos National Laboratory requests that the publisher identify this article as work performed under the auspices of the U.S. Department of Energy. Los Alamos National Laboratory strongly supports academic freedom and a researcher's right to publish; as an institution, however, the Laboratory does not endorse the viewpoint of a publication or guarantee its technical correctness. 


\section{Three-Dimensional Site Effects at Mortandad Canyon, NM: I. Validation against ambient noise recordings of topography effects}

Kami Mohammadi - Postdoctoral Research Associate, MCE, Caltech

Domniki Asimaki - Professor, MCE, Caltech

LANL PI: Carene Larmat - Scientist, EES-17, LANL

\section{Executive Summary:}

Observations from large earthquakes have shown that the presence of a strong topographic relief can significantly aggravate the catastrophic consequences of strong seismic motions. Structures on the tops of hills, ridges, and canyons, for example, have suffered systematically greater damage than similar structures at the hill bases or on level ground. Various earthquake recordings have confirmed the macroseismic observations, indicating systematic amplification of seismic motion over convex topographies, deamplification over concave topographic features, and complex amplification and deamplification patterns on hill slopes that result in significant differential motion. Despite the documented evidence of their role in elevating seismic risk, however, topography effects are not accounted for in the majority of seismic code provisions and microzonation studies, which are based instead on models of flat earth surface.

An experimental study conducted in 2014 on a ridge at Los Alamos National Laboratory near Los Alamos, New Mexico, showed systematic differences between the response of the ridge to ambient noise, and the response of flat ground sedimentary deposits in the vicinity of the ridge. Results brought forth the possibility of quantifying the amplitude and frequency range of topographic amplification using ambient vibrations. Our study used the experimental ambient noise results to validate a three-dimensional (3D) numerical model (digital twin) of the ridge. Building confidence in such a model will allow us to numerically study the effects of soil nonlinearity on the seismic response of the feature, and quantify the frequency and amplitude of topographic amplification for design level ground motions.

With the appropriate excitation, our numerical model was able to calculate the median amplitude and frequency response of the ridge with acceptable accuracy. We also used our simulations to show that in such a complex geomorphological environment, traditional ground response analyses in engineering design that are based on horizontal soil layers and flat ground surface cannot capture the spatial variability of ground shaking. Lastly, our results showed that field experiments based on ambient noise capture primarily the ground response to surface wave propagation, and as such may not be directly applicable to understand and quantify empirically the ground motion variability that is relevant to the design of critical infrastructure. 


\begin{abstract}
We study the three-dimensional (3D) site response of Mortandad Canyon, NM, located on a unique geomorphologic feature that comprises several inter-connected ridges separated by steeply-sloped canyons. We specifically build a finite volume 3D model based on the LANL Geologic Framework Model (GFM) which we subject to plane body wave, ambient noise random sources, Rayleigh wave incidence, and combinations thereof. Goal of this project is to test the accuracy of our model to predict complex 3D site amplification patterns by validating our simulated amplification spectrum (amplitude and frequency) against ambient noise measurements of topographic amplification. We also use our simulations to indicate that in such a complex geomorphological environment, traditional ground response analyses based on 1D wave propagation cannot capture the spatial variability of peak amplitude and resonant frequency that arise from the constructive and destructive interference between body and surface waves. With the appropriate excitation, our numerical model can be used to calculate the median amplitude and frequency field response with acceptable accuracy. More importantly, perhaps, our results suggest that ambient noise amplification captures primarily the effects of site response on surface wave propagation (here, Rayleigh waves) and as such, may not be directly applicable to evaluate empirically the body wave site response that is relevant to the design of critical infrastructure.
\end{abstract}

\title{
1. Introduction
}

The stratigraphy and mechanical properties of shallow geological formations, and the geometry of surface irregularities - together known as local site conditions - can significantly alter the characteristics of surface ground motion. Referred to as site effects, these alterations include phenomena such as large amplification of both horizontal and vertical motions, frequency content shifts and significant spatial variability of seismic ground motion, all of which are very important for the assessment of seismic risk in the seismic design of important surficial and subterranean infrastructures. Published theoretical studies on site effects that involve prominent topographic relief qualitatively agree with field recordings from natural and man-made seismic sources; quantitatively, however, they often underestimate the absolute level of site amplification up to an order of magnitude or more in some cases. A major part of this discrepancy stems from idealizations of the geometry, material properties, and incident motion characteristics that most theoretical studies make, perpetuating the misconception that topography effects and site response can be decoupled, studied independently, and superimposed to characterize local site effects. 
In this study, we build a three-dimensional (3D) deterministic numerical model with high-resolution surface geometry and subsurface stratigraphy that can be virtually probed to quantify site effects at Mortandad Canyon, NM; and we compare its response to ambient noise recorded on a prominent topographic feature. The goal is to explore whether and to what extent high-fidelity simulations can capture quantitatively the frequency and amplitude characteristics of 3D site amplification. Our overarching goal is to establish a validated model to quantify site amplification in the area under various seismic scenarios, including strong shaking generated by the adjacent Pajarito fault system.

\section{Numerical model for seismic wave propagation in 3D heterogeneous media}

The Mortandad Canyon is located on a unique geomorphologic setting comprising several inter-connected ridges separated by steeply-sloped canyons. The surface topography is accompanied by a complex subsurface geology of successive igneous (e.g., basalt, tuff) and sedimentary units. Seismic wave propagation through such irregular boundaries/interfaces with large stiffness contrasts is characterized by a complex scattered wavefield. The constructive and destructive interferences of resultant body, interface, and surface waves give rise to a spatially variable ground motion pattern whose characteristic length is determined by the relative scale of the dominant wavelength and the geometry characteristics that the said wavelength excites. To quantify this frequency-dependent amplification pattern at LANL, one needs to account for the complex coupling between subsurface stratigraphy and surface topography through a numerical model that appropriately resolves the seismic wave propagation in $3 \mathrm{D}$ media with both surface topography and subsurface heterogeneity for a wide range of excitation frequencies. Such analysis needs to consider various wave types generated by different source mechanisms. We here use the explicit finite volume method FLAC3D that combines the simplicity and robustness of finite difference method with the flexibility of finite element method to model wave-propagation phenomena in heterogeneous media.

For the surface topography and subsurface layering, we employed the 3D Geologic Framework Model (GFM), which has been developed by LANL through integrating large geologic and geophysical database over the past few years. Figure 1 shows the model that consists of 14 geologic units whose name, average depth, and elastic material properties are listed in Table 1. The excitation comprised a train of Ricker wavelets of different frequencies to cover the whole frequency range of interest, that is, $0.1-10 \mathrm{~Hz}$ (Figure 2). It should be noted that the maximum resolvable frequency is a function of minimum shear wave velocity of all geologic units $(700 \mathrm{~m} / \mathrm{s}$ at the ridge of experiment) as well as the size of finite volume zones $(15 \mathrm{~m})$. In fact, the required number of zones per minimum wavelength to prevent numerical dispersion and dissipation determines the maximum undistorted frequency in the numerical results. 
M 3 --- $1850 \mathrm{~m} / \mathrm{s}$

M 4 --- $1500 \mathrm{~m} / \mathrm{s}$

M 5 --- $1600 \mathrm{~m} / \mathrm{s}$

M 6 --- $1200 \mathrm{~m} / \mathrm{s}$

M 7 --- $1200 \mathrm{~m} / \mathrm{s}$

M 8 --- $1615 \mathrm{~m} / \mathrm{s}$

$\mathrm{M} 9$--- $1550 \mathrm{~m} / \mathrm{s}$

$\mathrm{M} 10---700 \mathrm{~m} / \mathrm{s}$

M11 --- $875 \mathrm{~m} / \mathrm{s}$

M12 --- $864 \mathrm{~m} / \mathrm{s}$

$\mathrm{M} 13$--- $762 \mathrm{~m} / \mathrm{s}$

M14 -- $701 \mathrm{~m} / \mathrm{s}$

M15 --- $358 \mathrm{~m} / \mathrm{s}$

$\mathrm{M} 16---411 \mathrm{~m} / \mathrm{s}$
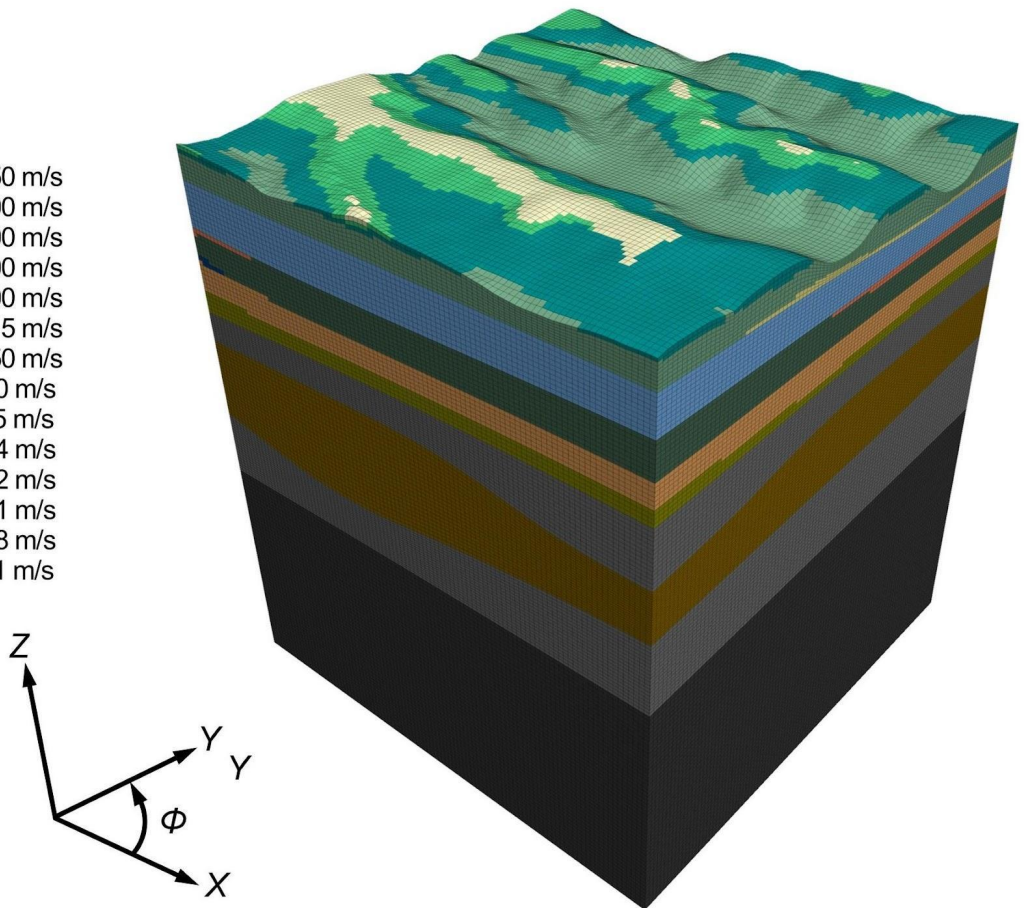

Figure 1. 3D velocity model of Mortandad Canyon
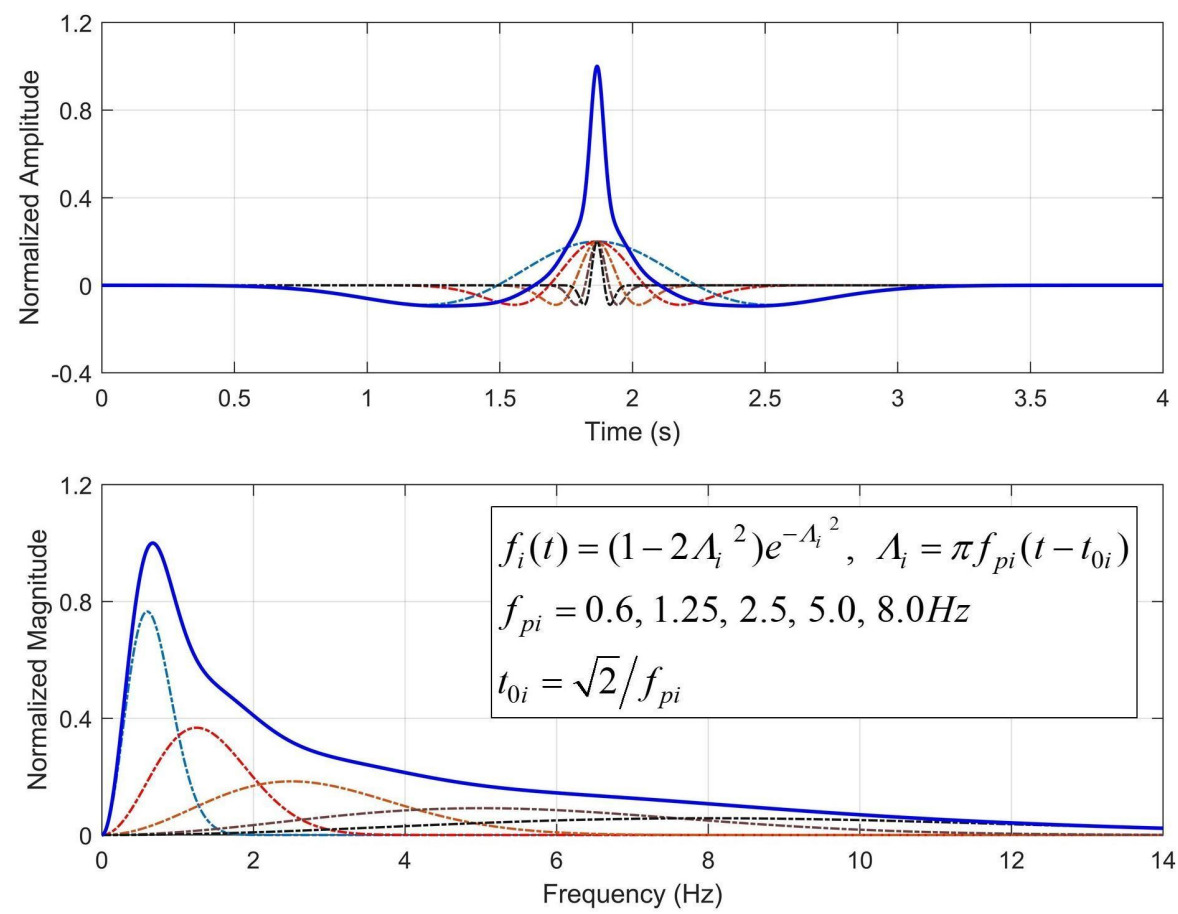

Figure 2. Ricker ensemble - isolated, smooth, and broadband pulse 
Table 1. Material properties of geologic units

\begin{tabular}{|c|c|c|c|c|c|c|c|}
\hline Material & Geologic Unit & Name & mean depth (m) & $\operatorname{vp}(\mathrm{m} / \mathrm{s})$ & vs $(\mathrm{m} / \mathrm{s})$ & Poisson & rho $\left(\mathrm{kg} / \mathrm{m}^{3}\right)$ \\
\hline 16 & Qbt4 & Tshirege Tuff & 17 & 720 & 411.5 & 0.257 & 1600 \\
\hline 15 & Qbt3 & Tshirege Tuff & 18 & 620 & 357.8 & 0.25 & 1600 \\
\hline 14 & Qbt2 & Tshirege Tuff & 18 & 1270 & 701 & 0.281 & 1700 \\
\hline 13 & Qbt1 & Tshirege Tuff & 65 & 1432.6 & 762 & 0.303 & 1700 \\
\hline 12 & Qct & Volcaniclastic sed. (fig 4-1) & 69 & 1439.6 & 863.8 & 0.219 & 1700 \\
\hline 11 & Qbo & Otowi (fig 4-1) & 125 & 1530 & 875 & 0.257 & 1700 \\
\hline 10 & Tpf3 & Puye on top of Cerros & 187 & 1212 & 700 & 0.25 & 1700 \\
\hline 9 & Tb4 & Cerros de Rio Basalt & 231 & 2895.6 & 1550 & 0.299 & 2500 \\
\hline 8 & Tvt2 & Dacite (Younger Tschicoma) & 245 & 2895.6 & 1615.4 & 0.274 & 2500 \\
\hline 7 & Tpf2 & Puye below Cerros & 296 & 2286 & 1200 & 0.31 & 2300 \\
\hline 6 & Tjfp & Sante Fe Flangomerate & 355 & 2078 & 1200 & 0.25 & 2300 \\
\hline 5 & Tb2 & lower basalt (younger miocene) & 614 & 3000 & 1600 & 0.301 & 2800 \\
\hline 4 & Tcar & Chamita - river deposit & 657 & 2800 & 1500 & 0.299 & 2700 \\
\hline 3 & Ttc & Chama - El Rito & 1263 & 3500 & 1850 & 0.306 & 2800 \\
\hline
\end{tabular}

\subsection{Validation against recorded ambient noise response}

We next evaluated the reliability of the numerical model to predict 3D site effects at the Mortandad canyon by comparing simulations against the existing field recordings. In absence of an appropriate reference station for site amplification (free-field), we applied the median reference method (MRM), and evaluated site amplification in the form of spectral amplification factors. We should note that such relative amplification ratios contain the combined effects of layering and topography that cannot be linearly decoupled; hence, we here refer to them as recorded 3D site effects instead of topography effects.

Assuming that the surface topography and subsurface stratigraphy - both extracted from GFM - are representative of the true site conditions, the goal is to find an excitation scenario that gives rise to the best match between theory and observation. We speculate that the ambient noise, comprising sufficient components of polarization and directivity, delineates the envelope of site response over the small-strain range. Thence, the average site response to a finite set of incident waves that cover the ensemble of frequency, polarization, and incident angles, should approach the ambient noise response as the dimension of parameter space increases.

To reproduce the amplitude and frequency of field recorded amplification, we first used an ensemble of plane shear waves of various azimuth angles (Section 2.1.1). We then tried a more complex diffuse field generated by random noise point sources in the bedrock layer (Section 2.1.2). Using the insight gained from the above excitations, we concluded that plane surface waves would be the most appropriate excitation to mimic the ambient noise recordings (Section 2.1.3). 


\subsubsection{Plane S wave incidence}

We first subject the numerical model to a set of incident vertically propagating shear plane waves of various polarization angles $\left(\varphi=0^{\circ}, 45^{\circ}, 90^{\circ}, 135^{\circ}\right)$. The relative orientation of topographic feature and incident angles determines which motion component (parallel/normal to the strike direction and vertical) undergoes the most site amplification. Figures $3 \mathrm{a}$ and $3 \mathrm{~b}$ show snapshots of scattered wavefield generated by shear plane wave polarized in $\mathrm{X}$ and $\mathrm{Y}$ directions at the instant of maximum amplification. These figures clearly show that the relative orientation of incident wave (polarization) and topographic feature (elongation) controls the amplification pattern on the surface. Smaller characteristic length of ridges in the Y direction results in larger amplification (red color) for incident wave polarization of $\varphi=90^{\circ}$. Considering stations 1, 2, 7 , and 7 (Figure 4) as reference stations in the MRM technique, we calculate the spectral amplification ratio for station 5 on top of the ridge. This station shows maximum amplification factors in both directions and thus it is a natural checkpoint for the validity of numerical results.

Figure 5 shows the comparison between experimental spectral ratios at station 5 and those calculated from the numerical modeling (mean black curve with one standard deviation for various polarization angles as a gray shadow). In both directions, the theoretical curve closely simulates the trend of experimental data up to the frequency resolution of the numerical model. This includes the blunted peak of lower amplitude in the direction of ridge strike (Figure 5a) where the ridge behaves like a single slope of $45^{\circ}$ angle. Perpendicular to the ridge strike, we have a dam-shaped topography whose characteristic length is smaller than the parallel direction and efficiently focuses the seismic energy. Therefore, the spectral amplification curve shows a single sharp peak of larger magnitude in this direction (Figure 5b). While the plane shear wave captures the primary and secondary peak frequencies well, the resultant amplification factors are much smaller than those observed in the field $(40 \%$ and $55 \%$ in the parallel and normal directions, respectively). The difference could be attributed to the lack of near surface diffracted seismic energy due to the direct reflection of single Ricker pulse. Furthermore, as we move

toward higher frequencies, the numerical curve deviates from the experimental one at about $2.5 \mathrm{~Hz}$, which is less than the maximum resolvable frequency of $5 \mathrm{~Hz}$. The divergence can be explained by different wave scattering mechanisms for two source types. In the case of plane shear wave, interaction of higher frequency wave packets with finer surface and subsurface features results in higher order peaks. For ambient noise, on the other hand, various wave components propagating in all azimuth and zenith directions cancel each other, which results in a smooth degradation of amplification curve over the higher frequency range. 

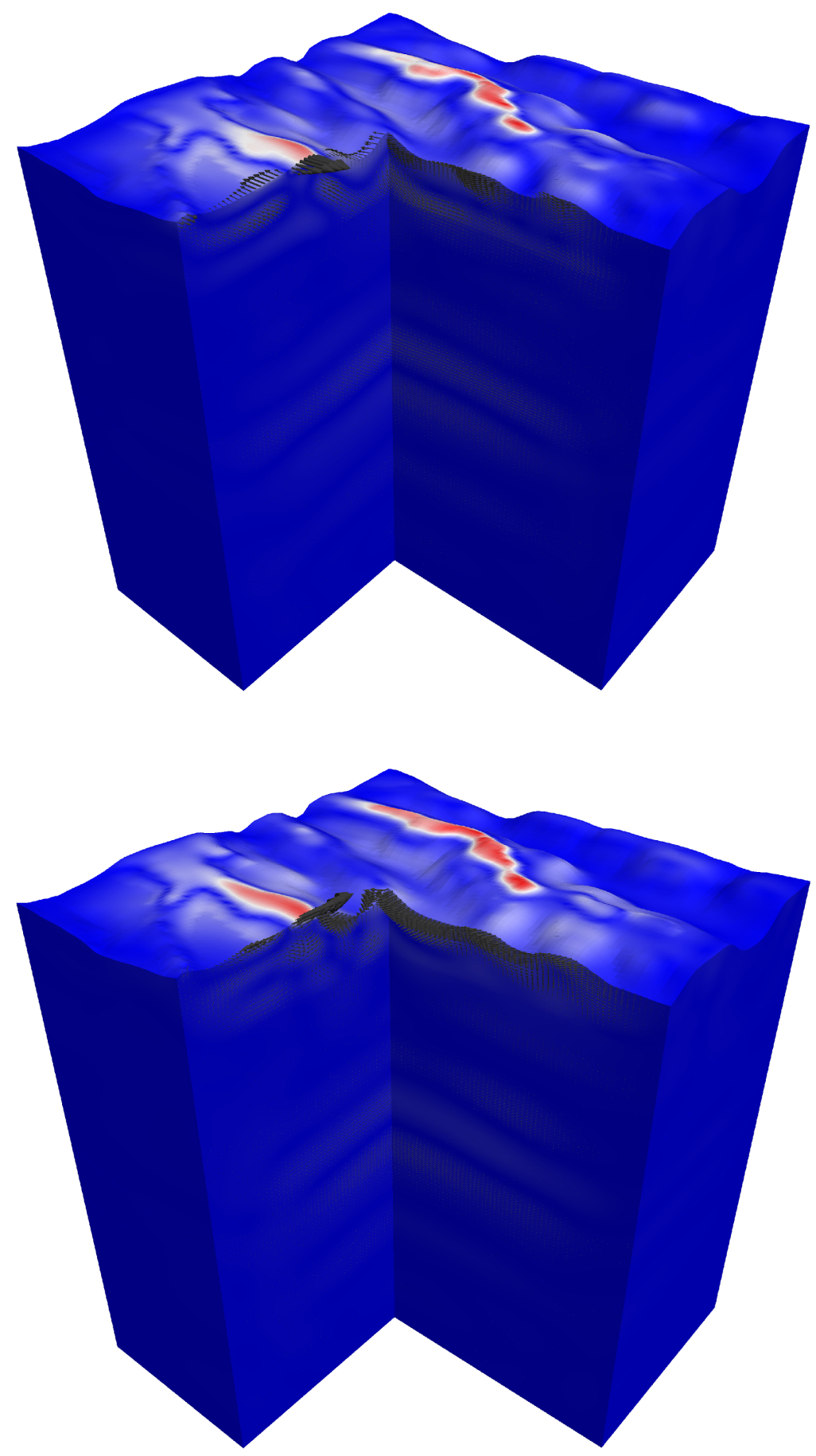

Figure 3. Snapshots of scattered wavefield generated by plane shear wave;

(a) polarization in X-direction, (b) polarization in Y-direction 


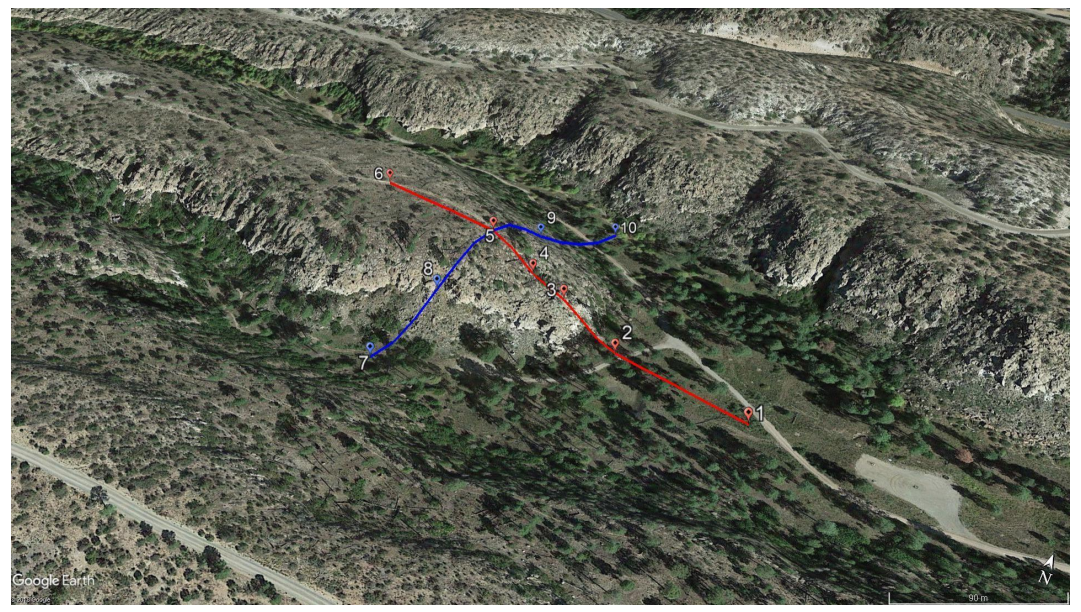

Figure 4. Location map of portable broadband seismometers that are aligned in two linear arrays parallel and normal to the ridge strike
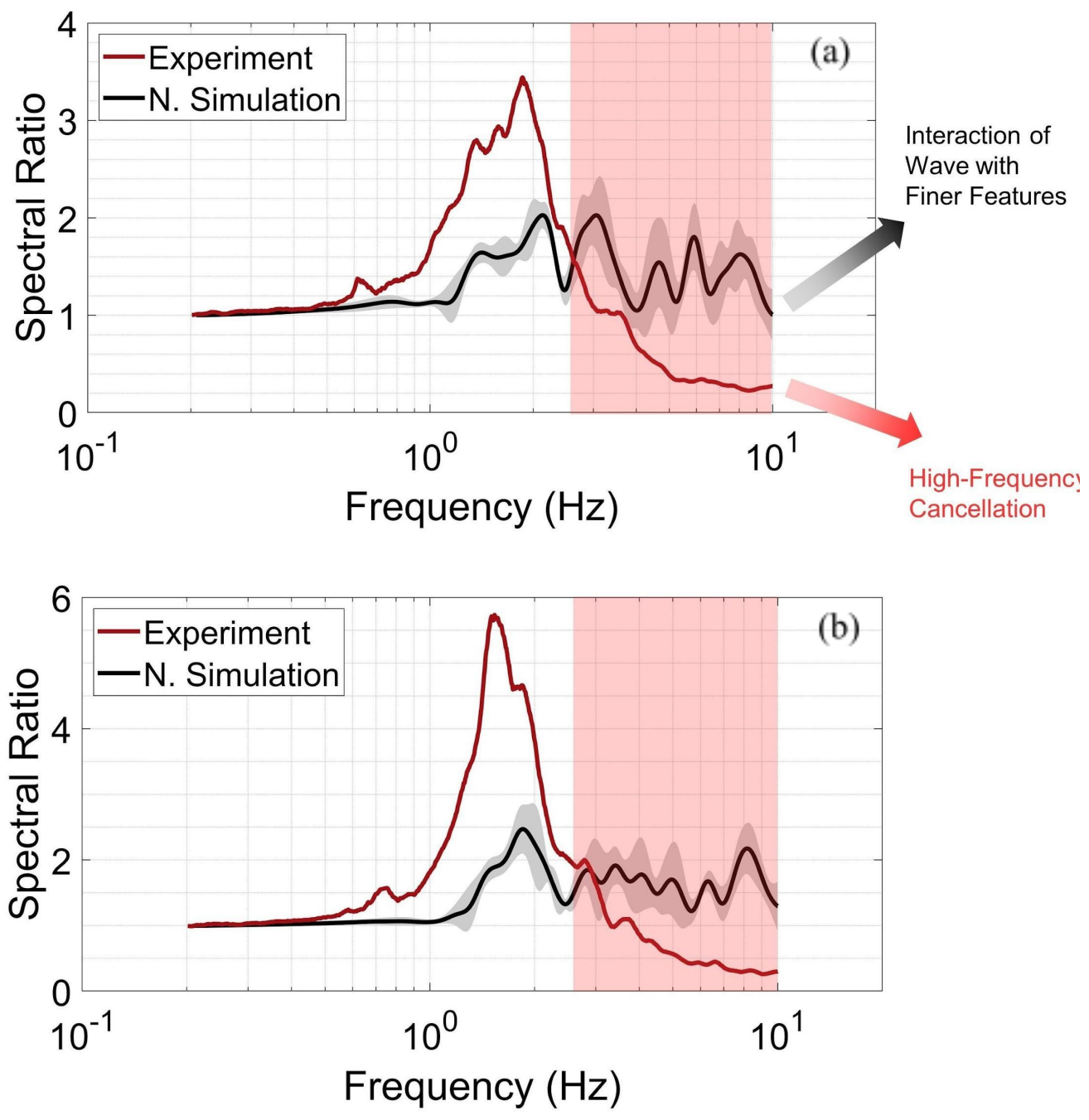
Figure 5. Comparison of spectral amplification ratio at station 5 - plane $\mathrm{S}$ wave;

(a) parallel component, (b) normal component

\subsection{1. $3 D / 1 D$ site response aggravation factors}

There is a common question in site response analysis regarding the validity of simple 1D models in predicting the true response of a site. We try to answer this question for the Mortandad canyon by calculating the ratio of the 3D site response at each point to the corresponding $1 \mathrm{D}$ site response. We use the GFM to extract subsurface layering information at each point $(15 \mathrm{~m} \times 15 \mathrm{~m}$ pixel). Figure 6 shows an example of this extraction for a pixel located in the middle of our numerical model. Moving vertically downward, we find a soil/rock column at this pixel consisting of various layers $\left(\mathrm{M}_{\mathrm{i}}\right)$ with different shear wave velocities, thicknesses, mass densities, and damping ratios. For each of these 1D columns, we calculate the surface to borehole transfer functions; examples are shown in Figure 7. For each pixel, we then have two site amplification functions, 3D response to plane wave incidence and simplified 1D spectral amplitudes. We can therefore calculate the ratio of these two (3D/1D) at each frequency and refer to it heretofore as 3D/1D aggravation factors. Results are shown in Figures 8a through 10a, each plotting the spatial distribution of $3 \mathrm{D} / 1 \mathrm{D}$ ratios at frequencies $1 \mathrm{~Hz}, 2 \mathrm{~Hz}$ and $3 \mathrm{~Hz}$, respectively.
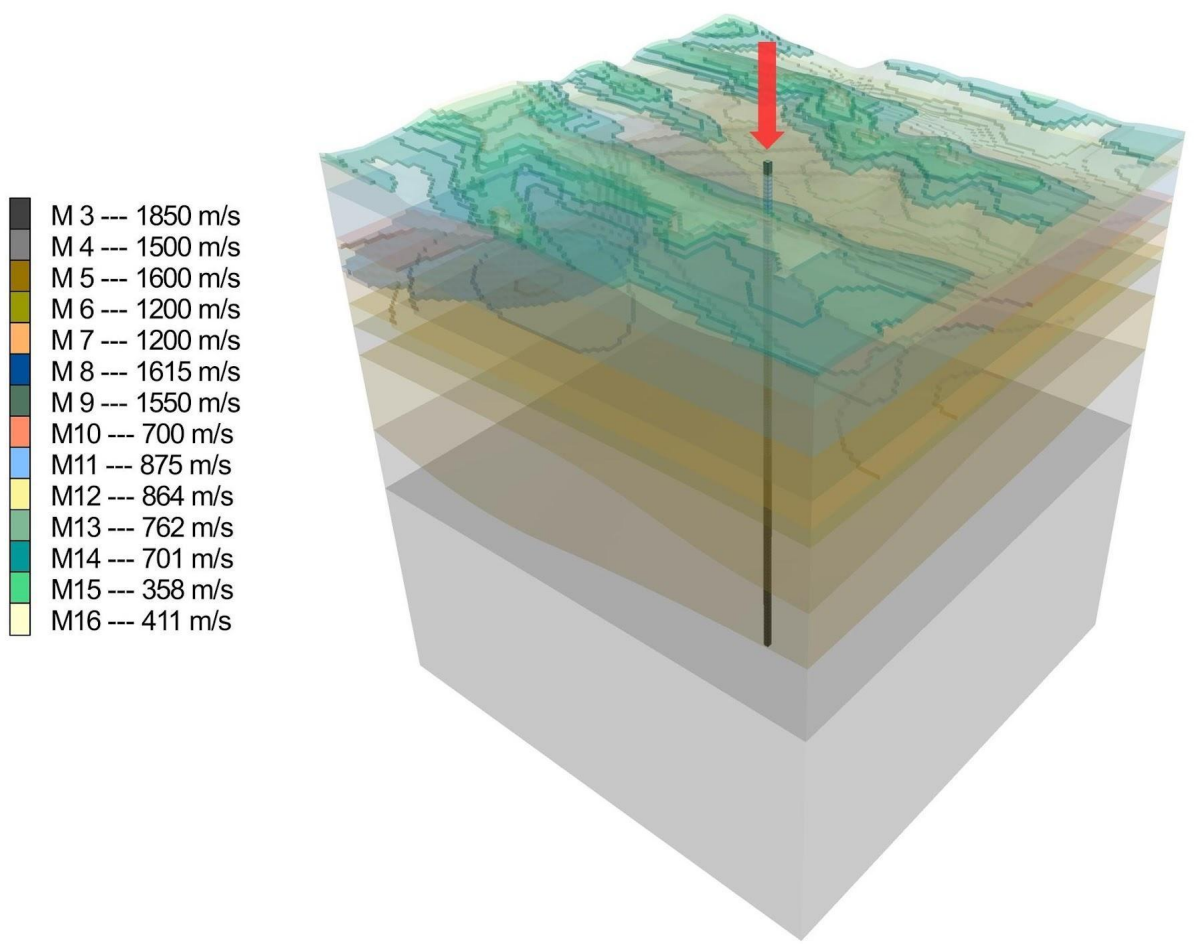

Figure 6. Extraction of 1D soil/rock column information from GFM 


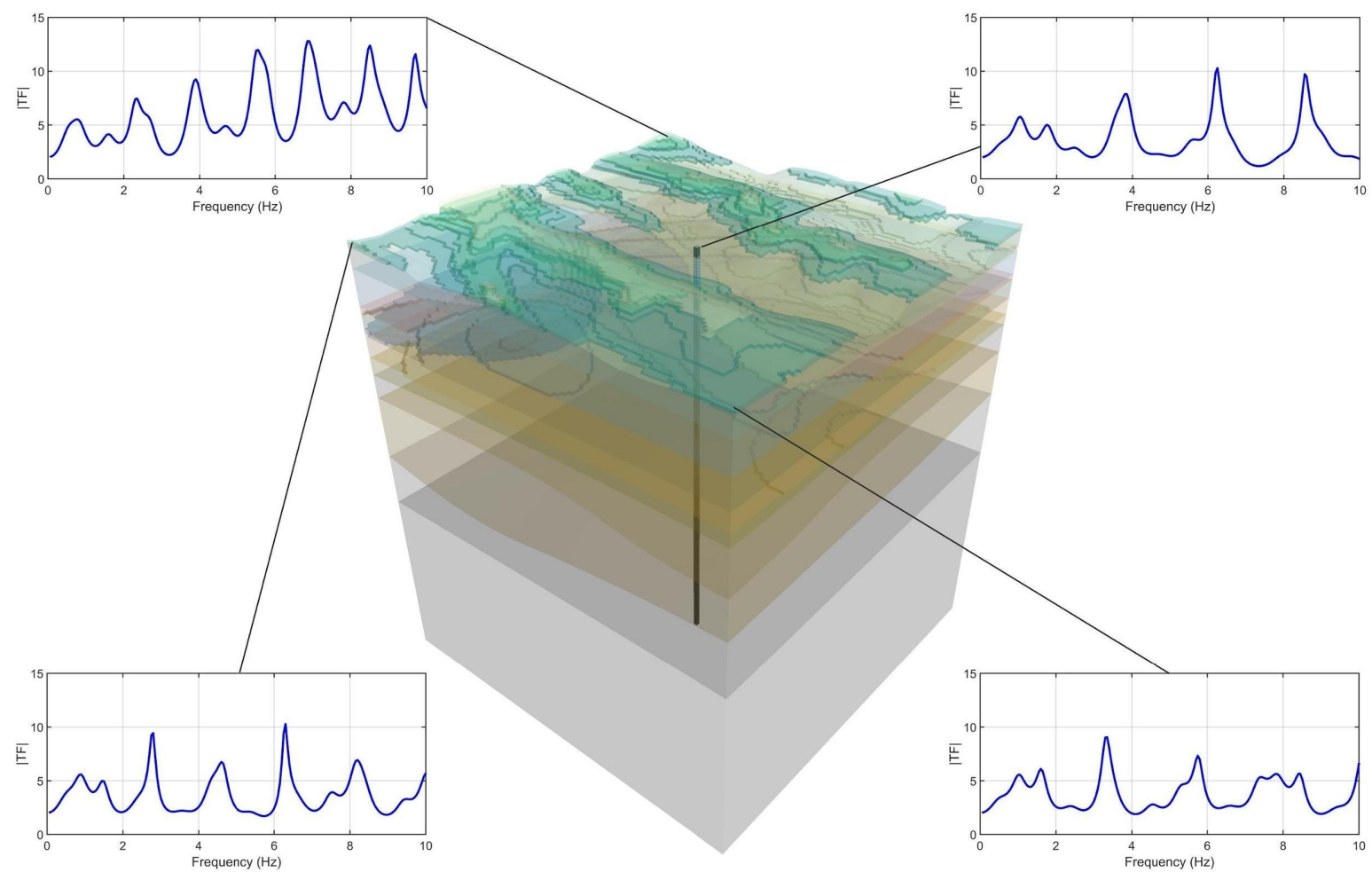

Figure 7. Examples of 1D transfer function

In these figures, the $3 \mathrm{D}$ response is calculated for the incident shear wave polarized in the Y-direction. This polarization gives rise to the maximum overall amplification over the frequency range of interest. As we increase the frequency, the incoming wave sees features of smaller characteristic length and the resultant wave interference yields larger amplification. Furthermore, regions of sharp variation (singularity) in the amplification ratio become more distinct. For example, look at the amplified region at coordinates $(0.3 \mathrm{~km}, 1.1 \mathrm{~km})$ in $\mathrm{f}=3.0 \mathrm{~Hz}$ plot (Figure 10a). These non-physical sharp changes reflect the limitations of 1D site response to correctly capture the true response of $3 \mathrm{D}$ feature.

Part $\mathrm{b}$ in Figures 8 to 10 show another measure of 3D/1D aggravation effects, 3D response normalized by the rock outcrop ( $\mathrm{RO}$ ) motion, 3D/RO (assuming a homogeneous halfspace as rock outcrop, the denominator is twice the amplitude of the incident wave). In the lower frequency range, $3 \mathrm{D} / \mathrm{RO}$ amplification and $3 \mathrm{D} / 1 \mathrm{D}$ aggravation ratios are similar, meaning that there is little spatial variability of $1 \mathrm{D}$ site response in this frequency range. As we move to higher frequencies, each 1D column shows a distinct response, which in turn, results in higher discrepancies between two ratios. Note that since the denominator of $3 \mathrm{D} / \mathrm{RO}$ is common across all pixels, this ratio illuminates the convex topographies (focusing effects) relative to flat ground and convex features (defocusing) and as such, is closer to what one could refer to as 'topographic amplification' (although still coupled with stratigraphy). 

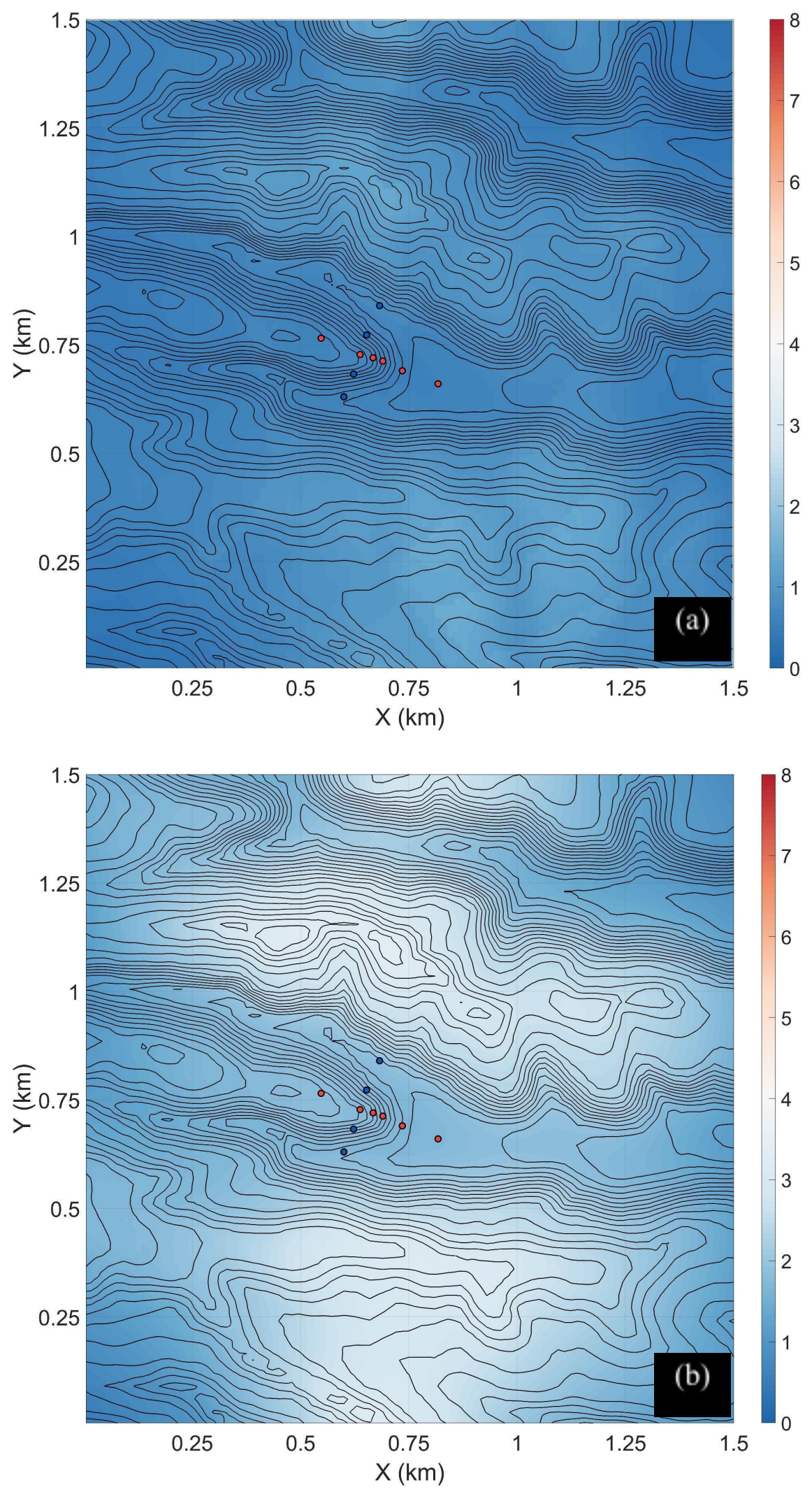
Figure 8. $3 \mathrm{D}$ site effects $-\mathrm{f}=1 \mathrm{~Hz}$; (a) $3 \mathrm{D} / 1 \mathrm{D}$ aggravation, (b) $3 \mathrm{D} / \mathrm{RO}$ amplification

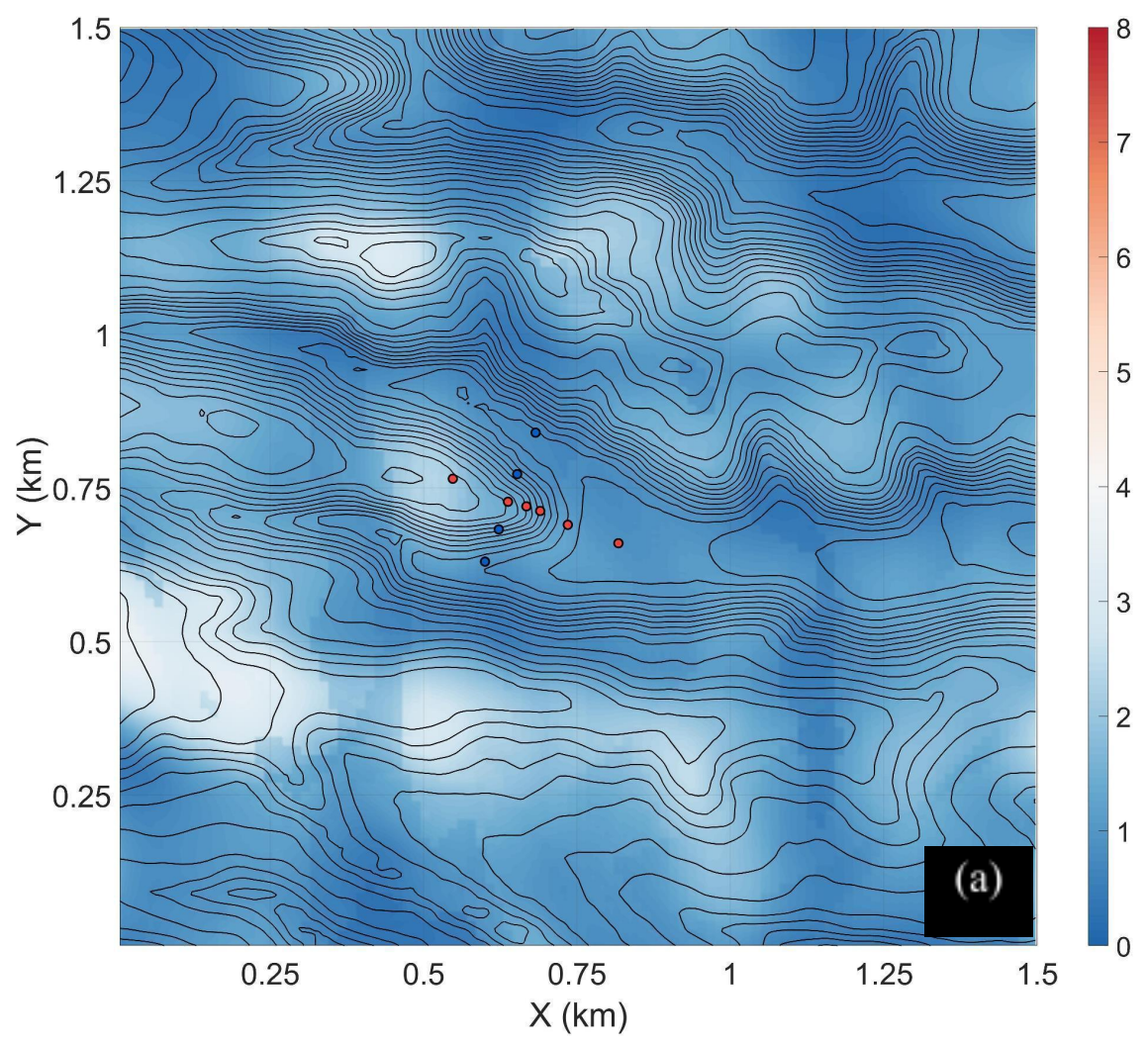




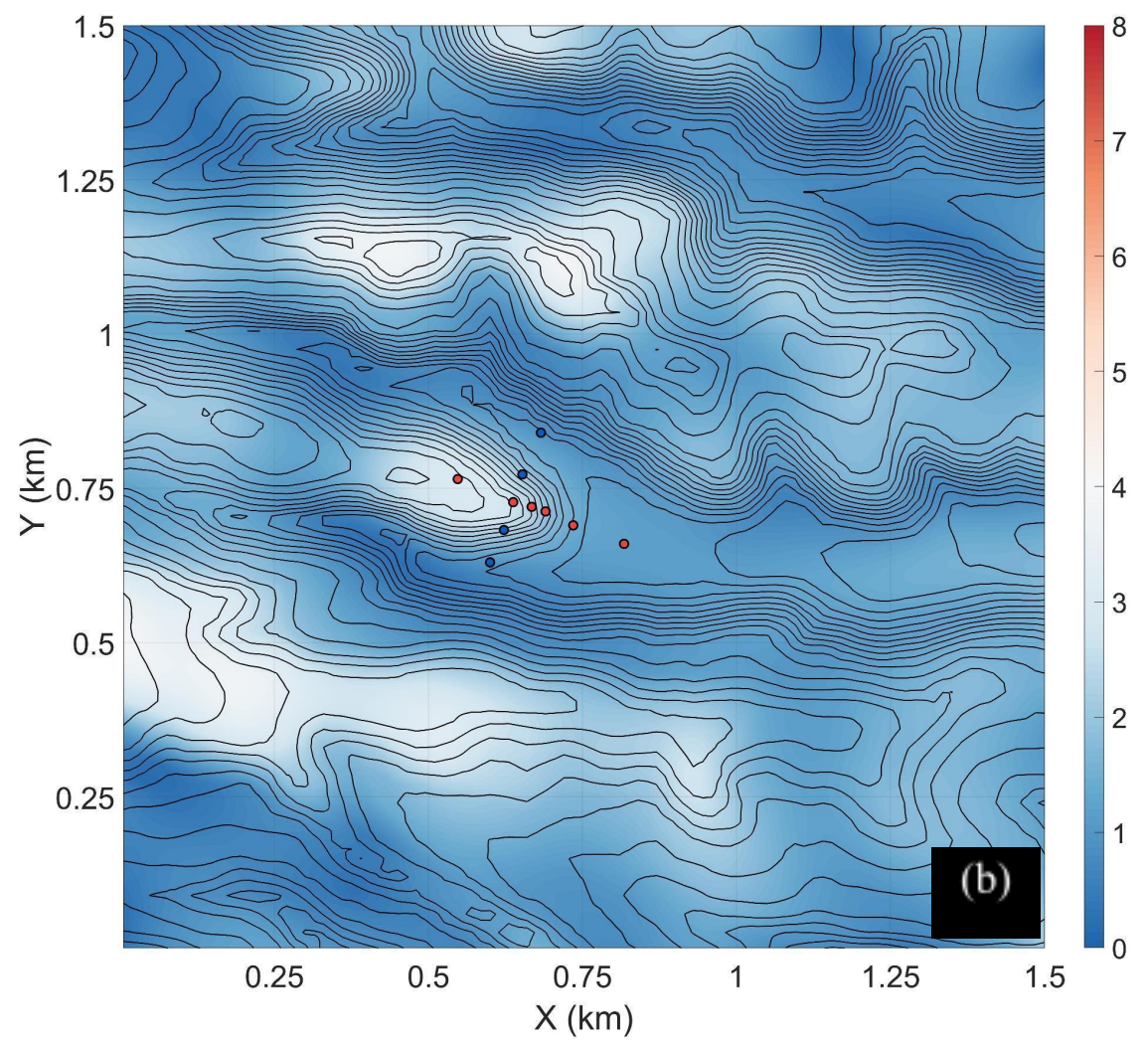

Figure 9. 3D site effects $-\mathrm{f}=2 \mathrm{~Hz}$; (a) 3D/1D aggravation, (b) 3D/RO amplification 

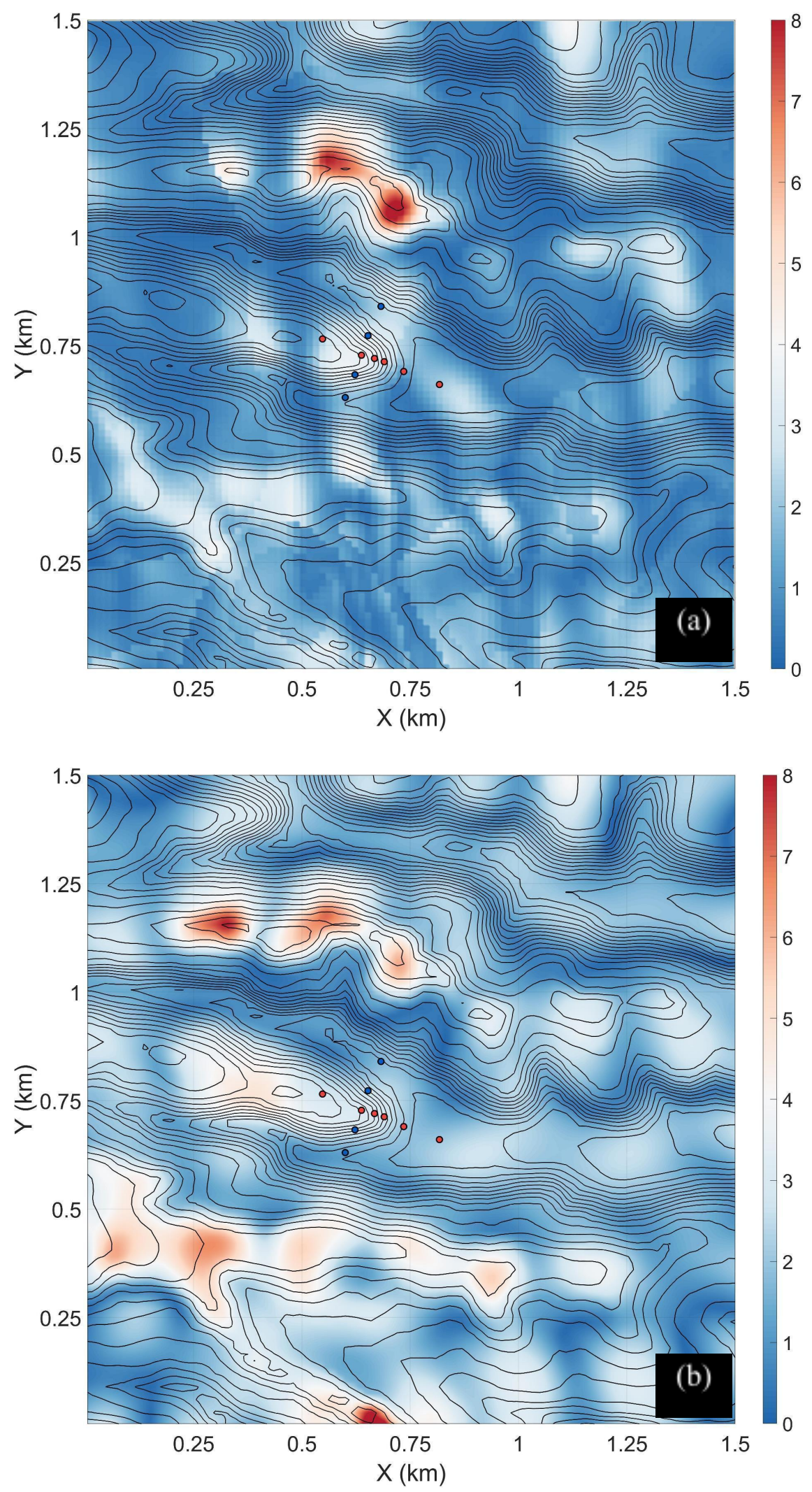


\section{$3 \mathrm{D}$ site effects $-\mathrm{f}=3 \mathrm{~Hz}$; (a) 3D/1D aggravation, (b) 3D/RO amplification}

Figure 11 shows a summary of maximum amplification factors $(3 \mathrm{D} / 1 \mathrm{D}$ peak ratio) for a set of azimuth angles $\left(\varphi=0^{\circ}, 45^{\circ}, 90^{\circ}, 135^{\circ}\right)$.) and frequencies ( $\mathrm{f}=0.5 \mathrm{~Hz}, 1.0 \mathrm{~Hz}, 2.0 \mathrm{~Hz}, 3.0 \mathrm{~Hz}$ ). While the polarization along the Y-axis $\left(\varphi=90^{\circ}\right)$ shows the absolute maximum amplification, other azimuth angles have larger amplification at certain frequencies. In fact, to have a complete picture of site response at Mortandad canyon, we need to consider various polarization angles. For example, polarization angles $45^{\circ}$ and $135^{\circ}$ show larger amplification at frequency $\mathrm{f}=3.0 \mathrm{~Hz}$ where the incoming wave captures the local feature along the same direction (look at the match between polarization arrow and local alignment of surface topography).

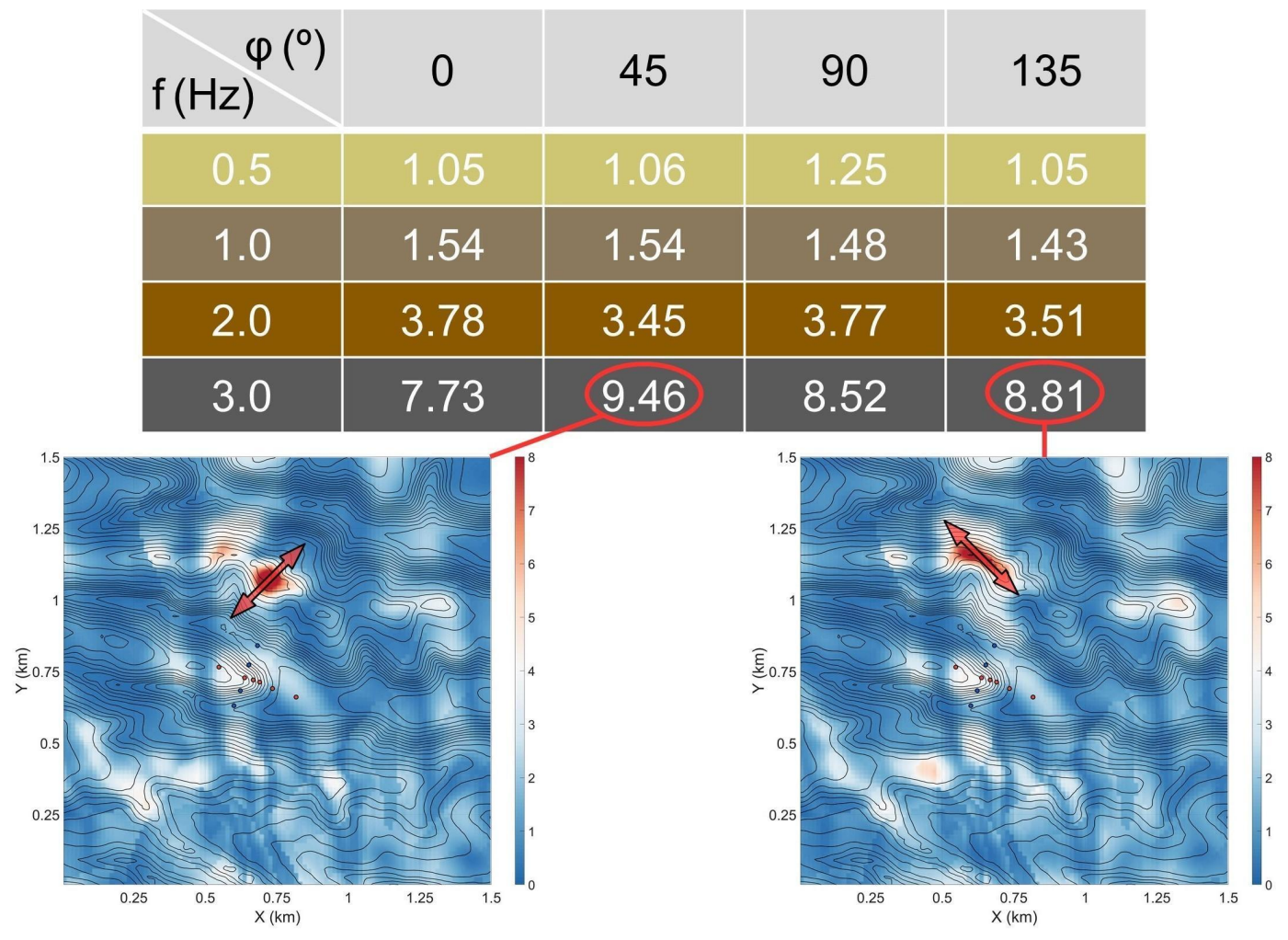

Figure 11. 3D/1D aggravation for all polarization angles and frequencies

\subsection{Point sources of ambient noise}

In the second part of this study, we compare the field measurements to synthetic site response using ambient noise as a source of excitation. To model the ambient noise, we use $N$ (variable) point sources located randomly in the bedrock layer M3 (Figure 12). The directions of applied kinematic sources (azimuth and zenith angles of velocity vector) are also random. All random variables are extracted from the uniform distribution as suggested by previous studies in Seismic Interferometry. The time history of each noise source (180s long) is generated by taking random amplitude and phase in Frequency domain, low-pass filtering below $10 \mathrm{~Hz}$ (maximum frequency 
of interest), transforming back to time domain, and placing randomly in the total running time (300s). That is, the activation time of each noise source is also a random variable (Figure 13).

A sample of scattered wavefield generated by such random noise sources is shown in Figure 14. As we can see, while the scattered field is distributed all over the domain with various wave components, the general amplification pattern is consistent with what we know as topographic amplification, that is, larger amplitudes on convex parts and smaller on canyons and flat ground. This means that even with ambient noise excitation we are able to extract information about the seismic characteristic of a site. Figure 15 shows the comparison of spectral amplification results (numerical vs. experiment) at station 5 on top of the ridge where maximum $3 \mathrm{D}$ amplification is expected. In the perpendicular direction, with smaller characteristic length and larger amplification, we can see improvements on the simulated peak frequency and the overall trend of the amplification curve compared to the case of plane wave incident. Furthermore, as we expected, using ambient noise sources results in the high frequency cancellation and the degradation of amplification curve similar to the experimental data. In the parallel direction, however, we have a clear shift of peak frequency with respect to the observed spectral curve indicating that to get a closer match between theory and observation, the scattered energy generated by ambient noise should be trapped within a surface feature.

In both directions, the amplitude of spectral ratio is still below the observed values. There are several potential explanations for the observed discrepancy between ambient noise simulations and field observations including short recording time, inadequate number of noise sources, and surface wave effects. In the next part, we focus on the effects of near-surface energy concentration of surface waves on the synthetic ground motion amplification relative to the field recordings. 


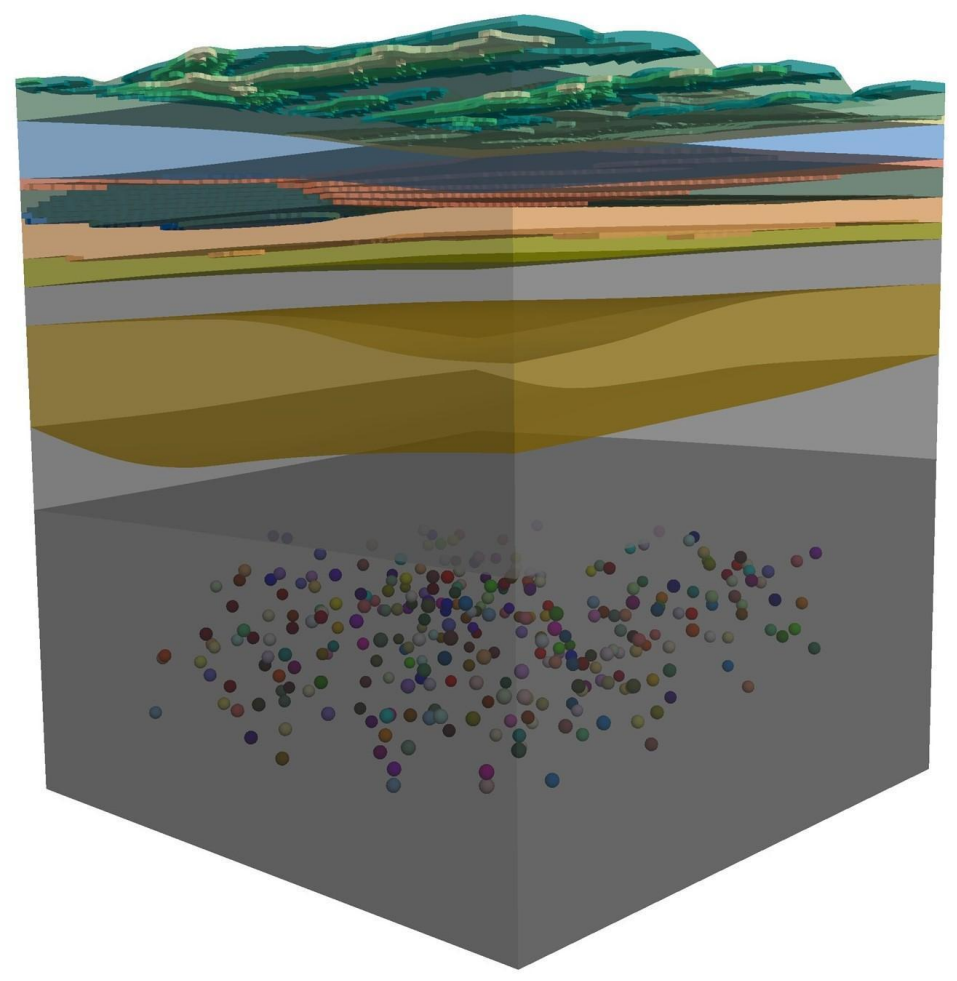

Figure 12. Noise sources randomly distributed in layer M3
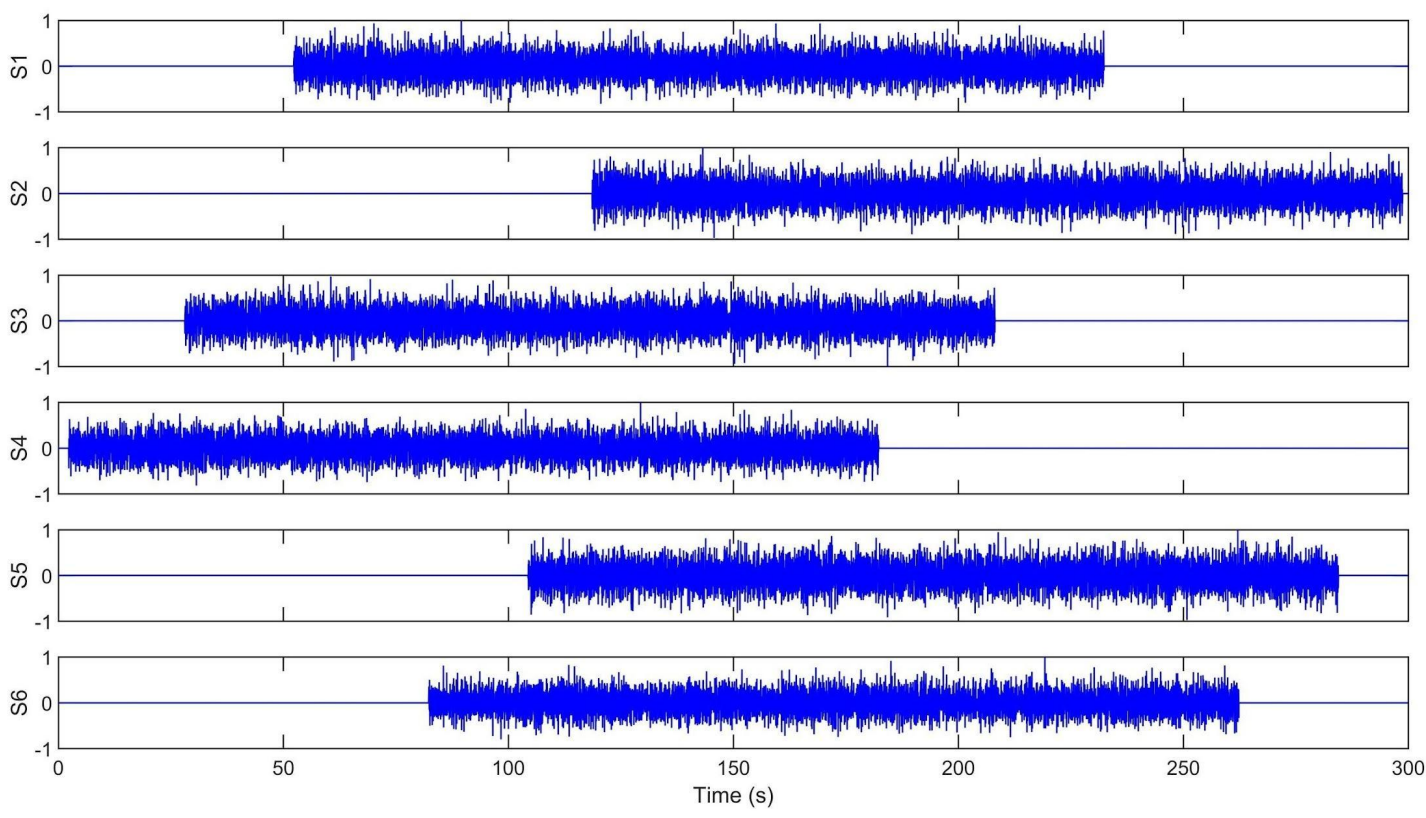

Figure 13. Samples of noise time history with characteristics extracted from uniform distribution 


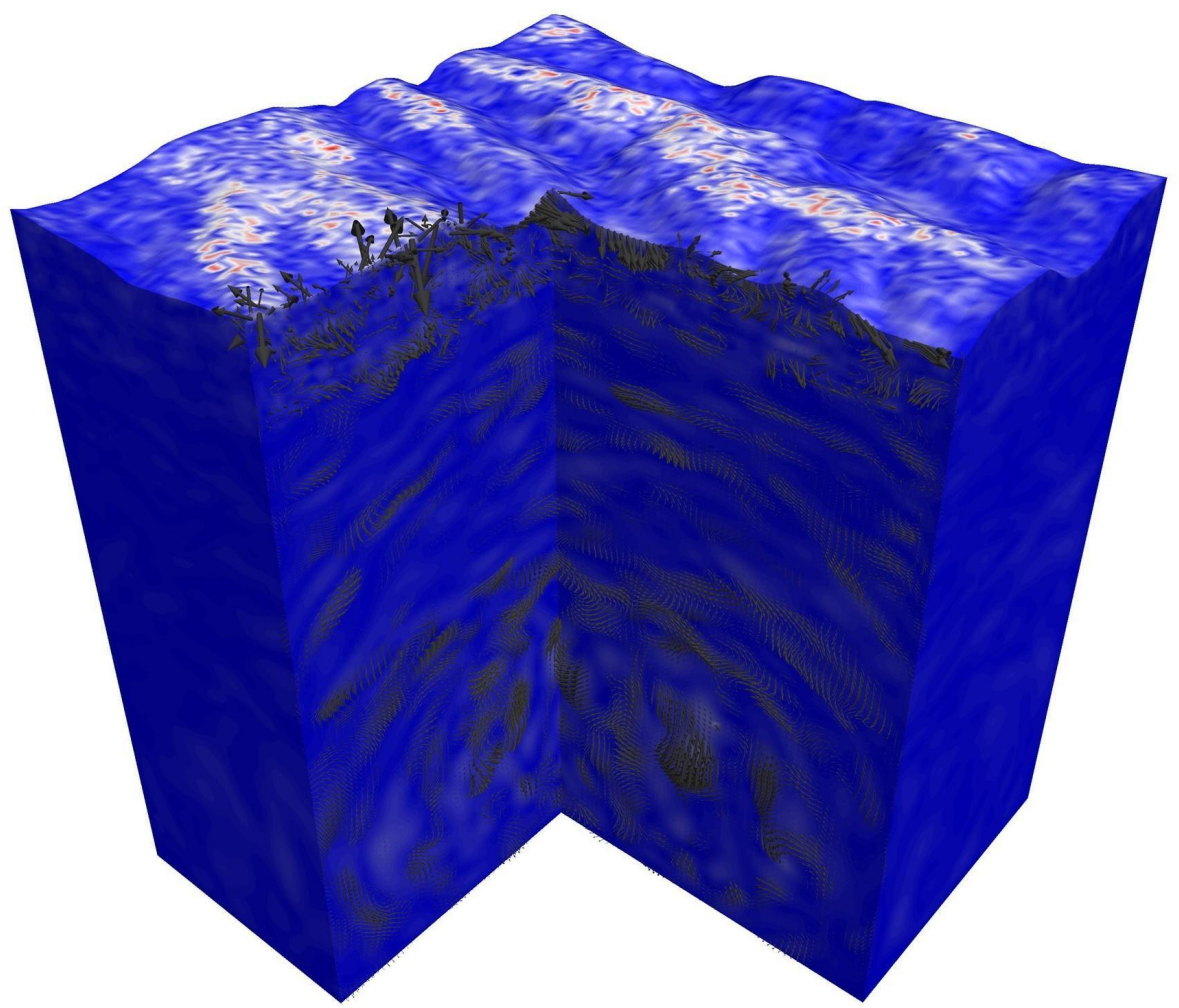

Figure 14. Snapshots of scattered wavefield generated by random noise sources

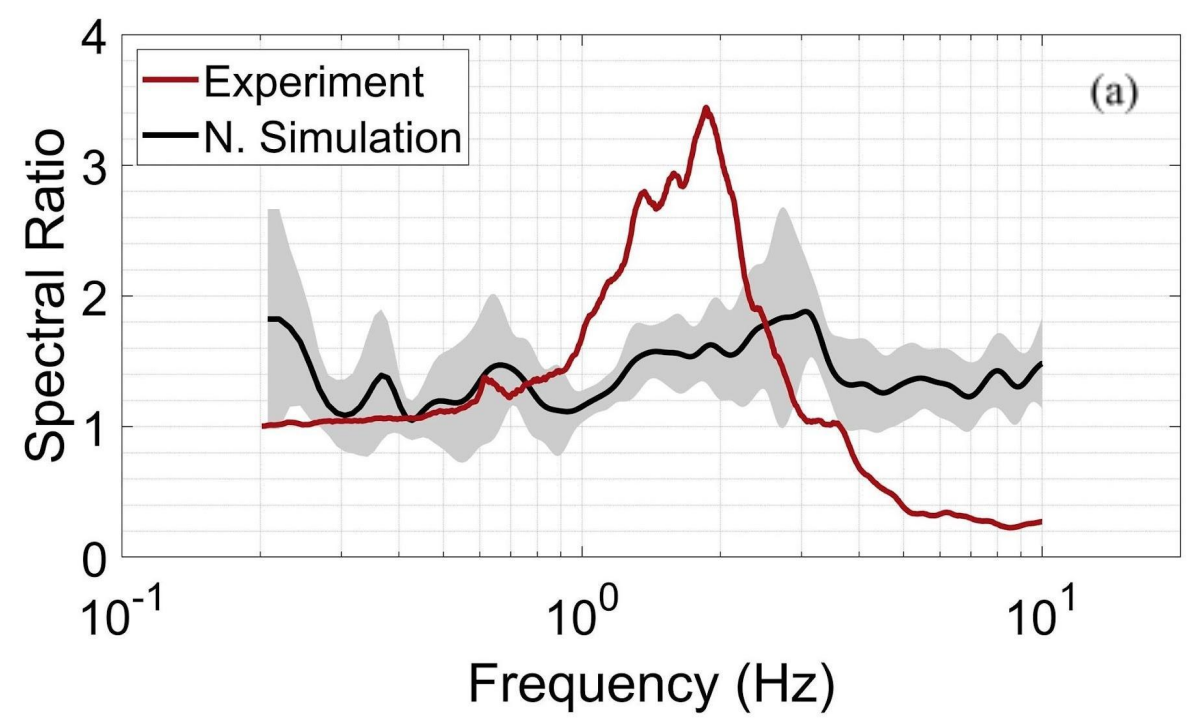




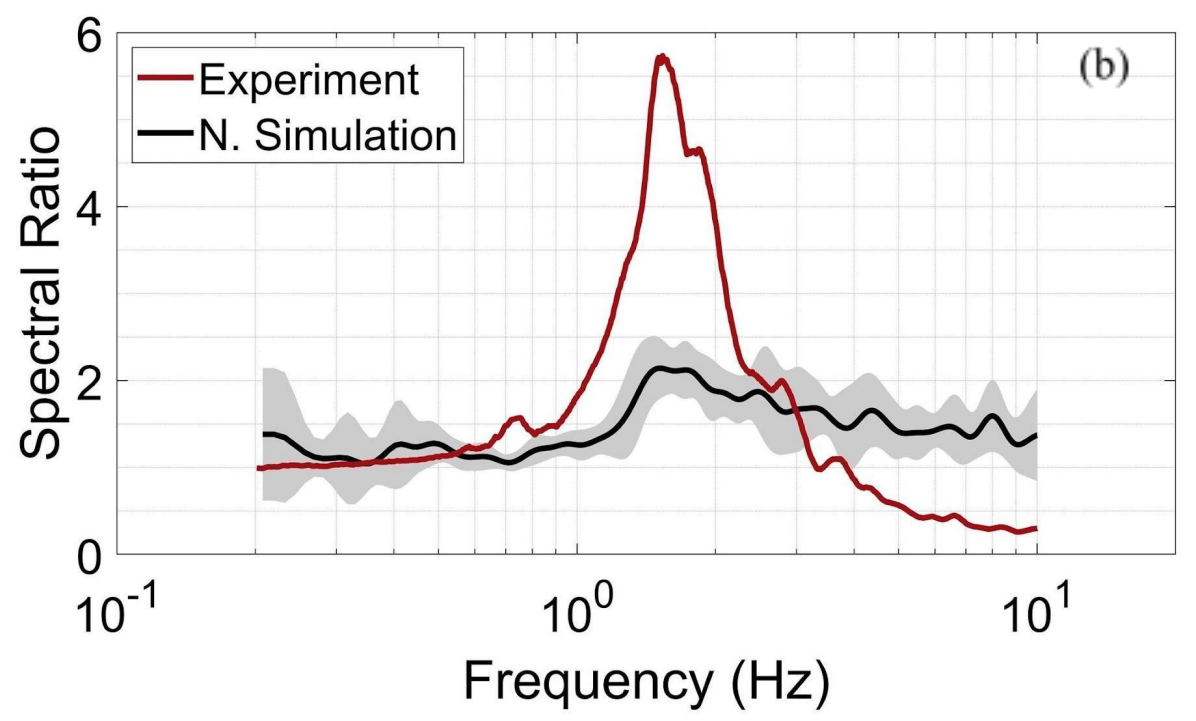

Figure 15. Comparison of spectral amplification ratio at station 5 - ambient noise; (a) parallel component, (b) normal component

\subsection{Pure Rayleigh wave incidence}

The results presented in sections 2.2 and 2.3 show that both plane shear wave and ambient noise can capture the general trend of spectral amplification at the Mortandad canyon site, especially the frequency of primary and secondary peaks. However, they both underestimate the magnitude of amplification by $40 \%-55 \%$. This lower amplification is mostly related to the lack of near-surface seismic energy in those excitation scenarios. To make our numerical model closer to actual site conditions and thus obtain a better match between theory and observation, we apply surface excitation in the form of plane Rayleigh wave incidence. The excitation planes for various Rayleigh wave polarizations are shown in Figure 16. It should be noted that the propagation and polarization angles and their relative alignments with respect to the ridge control the amplification pattern along the surface. While the Rayleigh wave is applied along four different planes, we expect a better match with actual conditions for inclined azimuth angles because of the inclination of surface features. Figure 17 show a snapshot of scattered wavefield generated by a plane Rayleigh wave propagating in Y-direction and polarizing in YZ-plane. The localized nature of seismic energy and the amplification on the convex parts of surface topography are clearly shown in this figure. Figure 18 shows the theory-observation comparison of spectral amplification at station 5. Using surface wave as a source of excitation, numerical results compare favorably to recorded amplification, both in terms of amplitude and frequency response. 

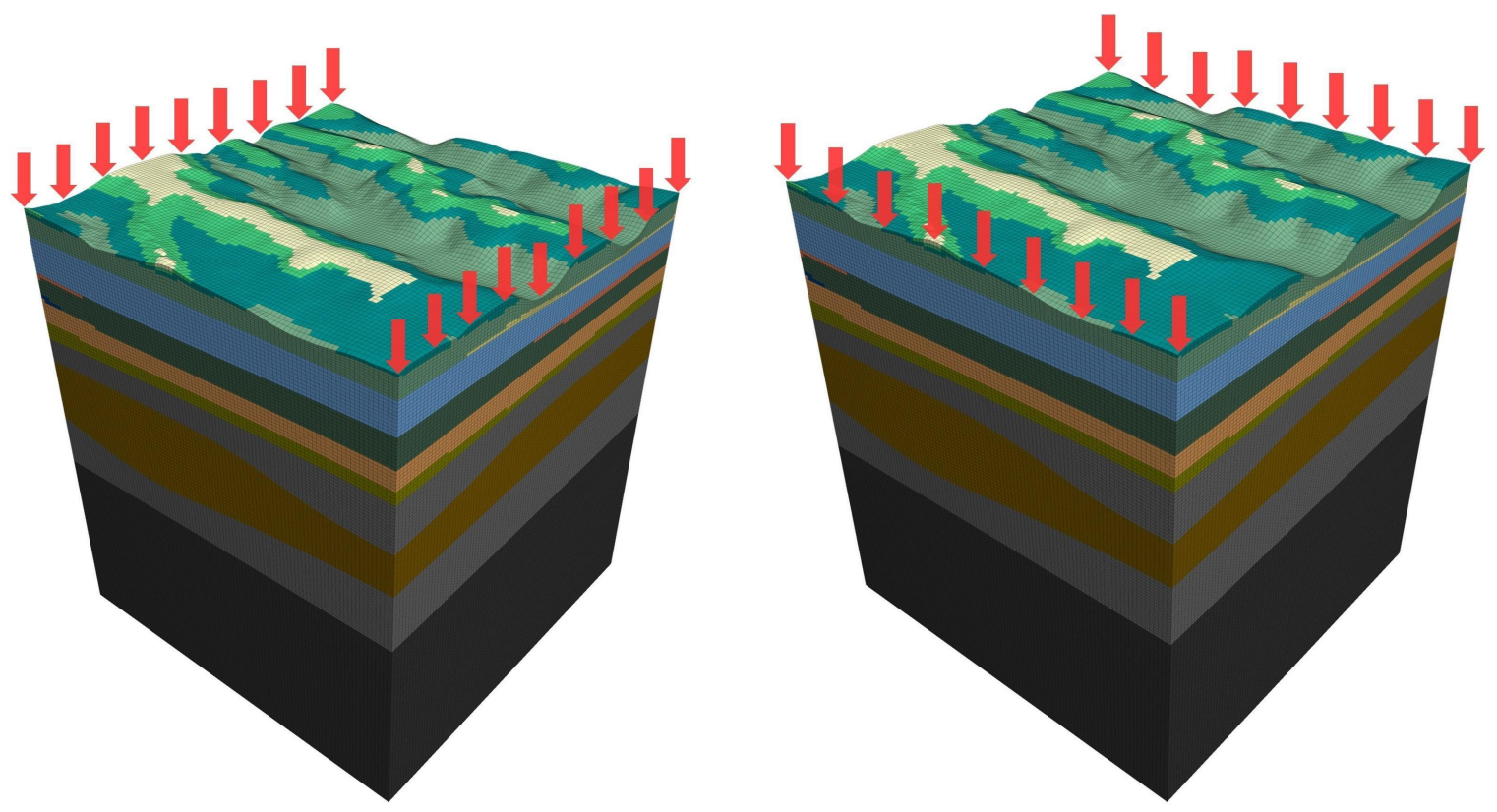

Figure 16. Planes of Rayleigh wave application; (a) polarization in XZ-plane, (b) polarization in YZ-plane

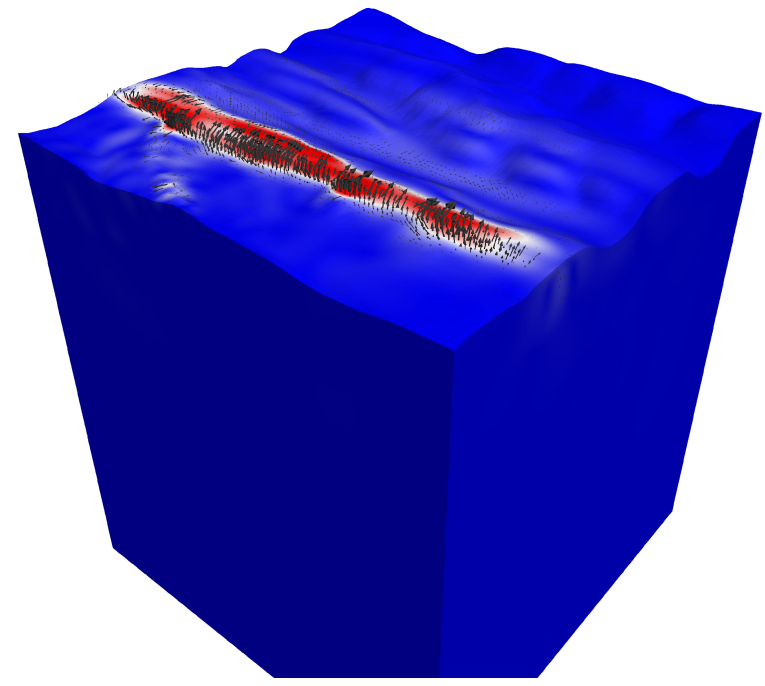

Figure 17. Snapshot of scattered wavefield generated by Rayleigh wave 

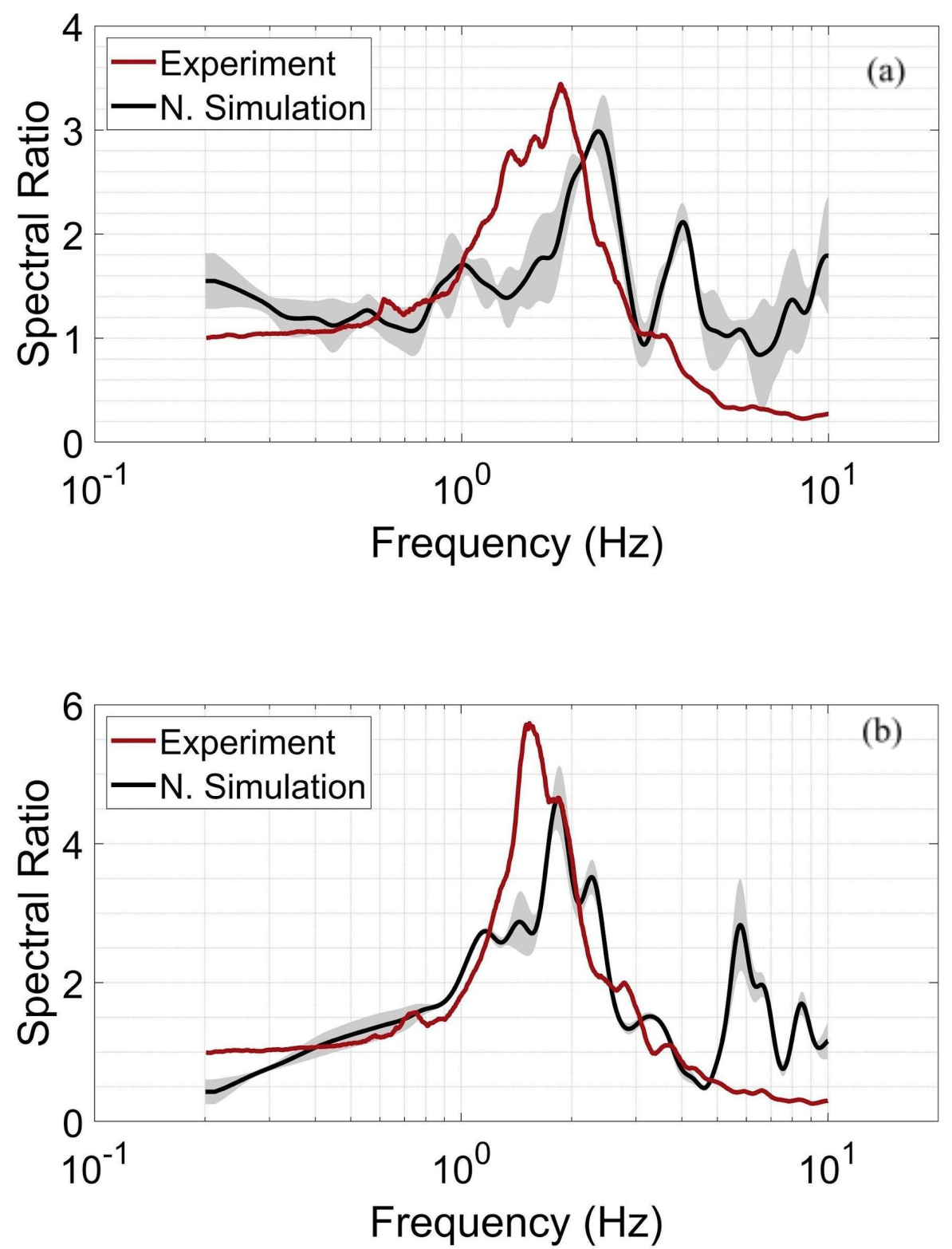

Figure 18. Comparison of spectral amplification ratio at station 5 - Rayleigh wave; (a) parallel component, (b) normal component 


\section{Conclusions}

We performed a set of 3D site response analyses at the Mortandad canyon, NM, using realistic surface topography and subsurface layering under various excitation scenarios. The results show that different characteristic lengths of surface and subsurface features can be recovered by any wave type, so long as it contains the corresponding wavelengths. The peak amplification values observed in the field, however, represent a more complex interaction between various wave components and thus they are hard to replicate using a numerical model. It is found that the large amplification at Mortandad canyon is mainly due to the diffraction of surface waves propagating in different directions and their near-surface energy concentration. The implication of this finding, other confirming the reliability of our deterministic numerical model, is that ambient noise amplification captures primarily the effects of site response on surface wave propagation (here, Rayleigh waves) and as such, may not be directly applicable to evaluate empirically the body wave site response that is relevant to the design of critical infrastructure. Open questions remain as to whether higher mode Rayleigh waves at inclined azimuth angles; post-critical inclined plane shear waves; or random noise sources applied at or near the surface (as opposed to the bedrock layer) could further improve our numerical predictions relative to the field observations. Also, translating the ambient noise amplification into meaningful 3D site response factors would be an important contribution to the state-of-practice of seismic hazard and risk assessment. Lastly, 3D/1D spatially varying aggravation factors confirm that the true seismic demand at the Mortandad canyon can be obtained only through a comprehensive 3D analysis, and that 1D site response at sites with pronounced convex topography and high subsurface impedance may underestimate the amplification at certain frequencies up to an order of magnitude. 
